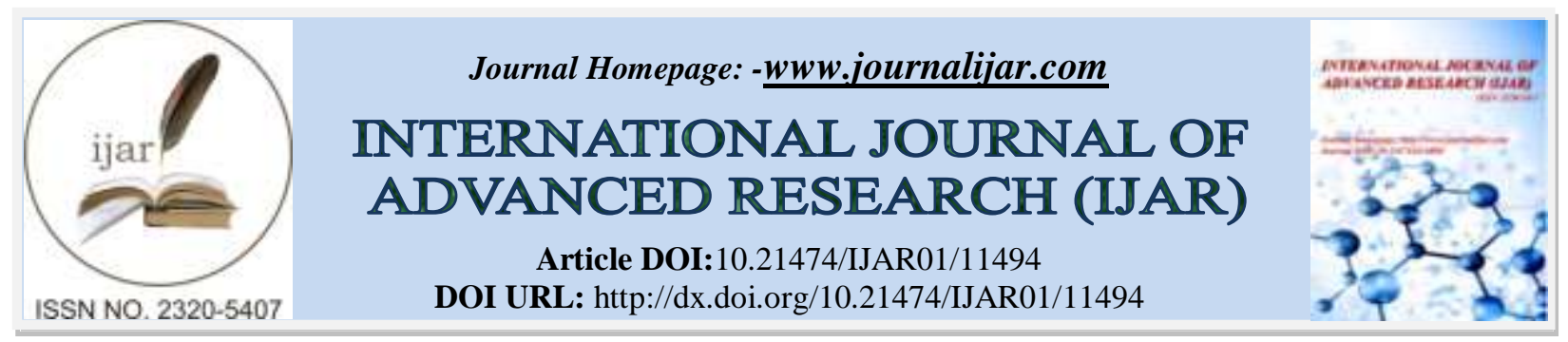

RESEARCH ARTICLE

\title{
EFFECT OF CARBAMAZEPINE ON FETAL KIDNEY
}

\author{
Singh Deepshikha ${ }^{1}$ and Mohanty Chhandamayee ${ }^{2}$ \\ 1. Department of Anatomy, AIIMS Patna. \\ 2. Department of Anatomy, Institute of Medical Sciences.Banaras Hindu University, Varanasi.
}

\section{Manuscript Info}

(.........................

Manuscript History

Received: 10 June 2020

Final Accepted: 14 July 2020

Published: August 2020

Key words:-

Carbamazepine, Teratogenic, Pregnancy,

Development

\section{Abstract}

Aims and Objectives: - Carbamazepine is one of the most widely used anti-epileptic drugs among women of child bearing age. This study aims to investigate the morphological and histopathological teratogenic effects of carbamazepine use during pregnancy.

Material and Method:-The healthy pregnant female mice were divided into two groups. The control group received equivalent quantity of distilled water by intraperitoneal route on $7^{\text {th }}$ day of gestation. Second group received $30 \mathrm{mg} / \mathrm{kg}$ of carbamazepine by intraperitoneal route on $7^{\text {th }}$ day of gestation. Fetuses were delivered on the $18^{\text {th }}$ day of gestation by hysterectomy. Each fetus was assessed for histopathological changes of kidney.

Results:-Kidney of fetal mice showed edematous changes. Glomeruli appeared to be atrophied and degeneration of epithelial lining of most tubules was evident.

Conclusion:-Histopathological changes in kidney of fetus are due to carbamazepine administered to the pregnant mice.

Copy Right, IJAR, 2020,. All rights reserved.

\section{Introduction:-}

Few drugs when administered during pregnancy may cause structural or functional alteration, reversible or irreversible, which may interfere with the normal growth, differentiation and development of the growing embryo, such phenomenon is called teratogenicity and such drugs are known as teratogens. Teratogens induce major morphological changes during embryonic period because it is the stage of rapid cellular division and differentiation (organogenesis),this effect has been laid to genetic factors, associated with the pathology itself (Macara,2000). The effect of teratogen ranges from no effect to malformation or intrauterine fetal death depending upon the dose (Harden et al.2009). Systems differentiation at the time of exposure determine pattern of congenital anomalies (Perucca, 2005). The mechanism of teratogenicity and human teratogenesis can be predicted by doing animal experiments in different animal species.

Some drugs are safe during pregnancy. There are five FDA (United States Food And Drug Administration) categories for drugs used during pregnancy. Carbamazepine is one of the most widely used anti-epileptic drugs among the women of child bearing age. It is highly effective for cryptogenic, symptomatic partial seizures, generalized tonic-clonic seizures, trigeminal neuralgia and mood disorders. It is a tricyclic anticonvulsant, neutral, lipid soluble compound that can easily pass the blood brain barrier and other membranes in the body (Hiremath et al., 2006). 
Off springs born to mothers with epilepsy are subject to a double risk, that is, to both epilepsy and the anti-epileptic drugs. The effects of neonatal direct toxicity and a high potential for behavior sequelae, related to language and learning capacity, are added to the teratogenic effects resulting from the anti-epileptic drugs exposure during pregnancy (Adab et al,.2001).Although the highest index of malformation in child born to mothers with epilepsy is associated to the mother exposure to anti-epileptic drugs, the interruption of the treatment may allow the convulsive fits and consequent fetal risks due to intrauterine hypoxia (Kaaja et al,.2004).

The aim of this study is to investigate developmental toxicity of carbamazepine for microstructure of vital organs.

\section{Materials and Methods:-}

The present study was conducted in the Department of Anatomy, of our institution after getting permission from ethical committee of university. The healthy female mice of 6-8 weeks of age, weighing 20-25g were subjected for the study. These animals were obtained from animal house of Department Of Anatomy, of our institution. The animal house was maintained at ambient temperature of $25 \pm 2^{\circ} \mathrm{C}$ and $50-60 \%$ relative humidity with $12: 12$ hour light: dark cycle.

For mating female albino mice were kept overnight with the male mice in a single plastic cage in the ratio of 2:1 (female: male=2:1). The mating and pregnancy success was approved by appearance of vaginal plug which was considered as day zero of the pregnancy. The pregnant mice were caged separately and allocated randomly into two equal groups. The first was control group: each pregnant mouse received $1 \mathrm{ml}$ of distilled water by intraperitoneal route on $7^{\text {th }}$ day of gestation and the second group received $30 \mathrm{mg} / \mathrm{kg}$ of carbamazepine by intraperitoneal route on $7^{\text {th }}$ day of gestation. Carbamazepine was in the tablet form $(100 \mathrm{mg})$ which was dissolved in distilled water and desired quantity of drug was administered.

On the $18^{\text {th }}$ day of gestation, all animals were killed by cervical dislocation and fetuses were delivered by hysterectomy. Each fetus was examined for gross malformation and euthanized by decapitation. Chest and abdominal viscera were exposed and removed by midline incision. After gross examination viscera were preserved in $10 \%$ neutral formalin solution for further histopathological studies. The tissue was processd and embedded in paraffin. Five micron thin sections were cut using rotary microtome and slides were prepared. Haematoxylin and eosin (H\&E) stained used for general histological study. The slides were examined under light microscope.

\section{Results:-}

The results indicated that carbamazepine administration during pregnancy, in the dosage of $30 \mathrm{mg} / \mathrm{kg}$ reduced weight gain in pregnant rats but it has not significantly changed the percentage of pre-implantation and postimplantation losses.

The carbamazepine administration in the dosage of $30 \mathrm{mg} / \mathrm{kg}$, during rats' pregnancy period, has not occasioned significant alteration in the external measures of the morphological parameters of the fetuses. Absence of syndactily and cleft palate and also no alteration related to eyes and ears were evident.

Kidney when examined grossly showed reduction in size of kidney of foetuses exposed to Carbamazepine, as shown in Fig.1. Light microscopic examination of the H\&E stained slides of kidney of the first (control) group showed normal renal structure of both cortex and medulla (fig.2). But mice kidney of the second group (treated) showed edematous changes. Glomeruli appeared to be atrophied and degeneration of epithelial lining of most tubules was evident (Fig.3). 


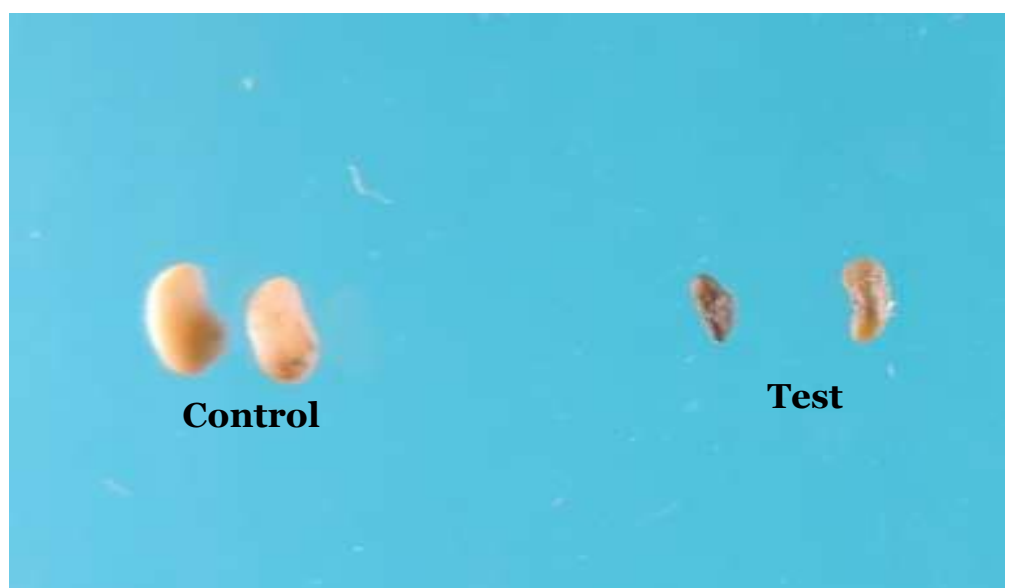

Figure 1:- Reduction in size of kidney of foetuses exposed to Carbamazepine.

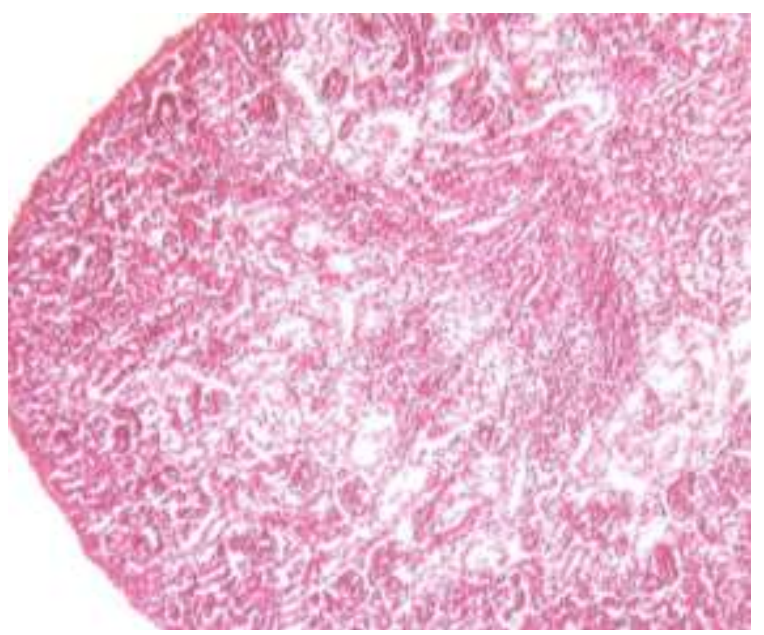

Figure 2:- Photomicrograph of control kidney shows normal developing nephrons in the outer cortex, fully developed nephron in inner cortex and loops of Henley in medulla (H \& Ex100).

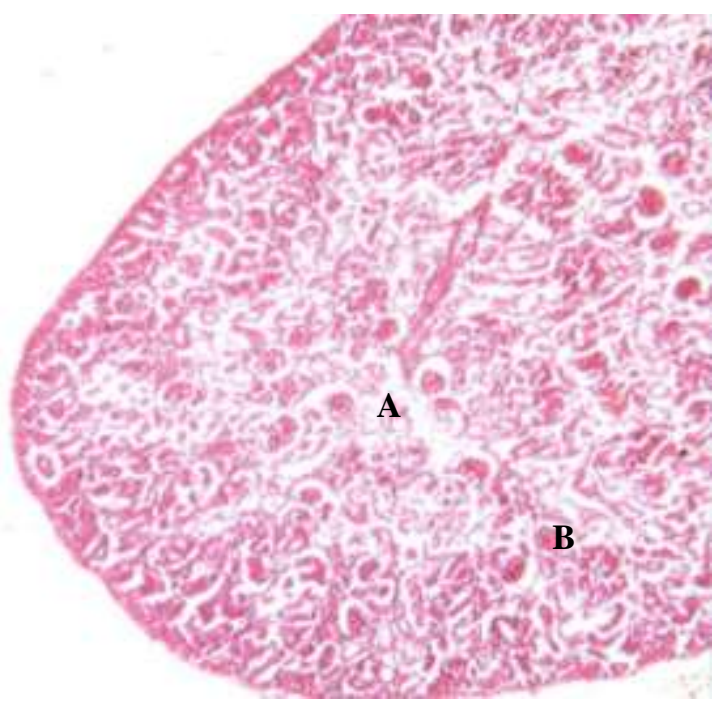

Figure 3:- Kidney of mice exposed to carbamazepine showing(H \& E X100) that shows edematous appearance of kidney (A) and clumping of Bowman's capsule (B). 


\section{Discussion:-}

Pregnant mice were exposed to Carbamazepine on gestational days $7^{\text {th }}, 8$ th and $9^{\text {th }}$, in low dose and high dose. Foetuses were collected on GD18.

Carbamazepine is efficacious in treatment of a variety of CNS disorders, as well as epileptic seizures. CBZ is usually well tolerated and therefore is also used in pregnant women (Eva Maňákováet al., 2011).

Carbamazepine is used as a monotherapyanticovulsant agent for treating epilepsy. It is associated with better seizure control and seizure rating score. It is considered as mood stabilizer also. The dosage of carbamazepine for adult ranged from 600-1600 mg/day. The starting dose is $200 \mathrm{mg}$ twice /day and increased by $200 \mathrm{mg} / \mathrm{day}$ every 3 to 5 days. Samrenet al.,(2003), Briggs et al.,(2008) recommended that carbamazepine is the drug of choice in pregnant women who requires anticonvulsant therapy for the first time. It may cause harm to the foetus because it crosses the placenta and then there is a high risk for use of carbamazepine during pregnancy.

The children of mothers taking antiepileptic drugs during pregnancy are at the increased risk of teratogenicity. The antiepileptic drugs cause anatomicaland behavioural effects by interacting with the genotype. Occurrence of defects depends upon susceptibility of genotype (Finnellet al., 1987).

The risk of birth defects due to antiepileptic drug exposure is higher in the first trimester in human and $6^{\text {th }}$ to $15^{\text {th }}$ day in rodents (Manson and Kang, 1994). None of the available antiepileptic drugs are completely safe during pregnancy (Dean et al., 2002, Maweret al., 2002, Morrow et al., 2006).

The mechanism by which CBZ exerts its teratogenicity is largely unknown. The study on Swiss albino mice indicated that similar to Phenytoin, CBZ could be biotransformed to a reactive teratogenic metabolite that might be responsible for the observed fetotoxicity (Finnell et al.,1995). The primary pathway of metabolism for CBZ involves the oxidative formation of carbamazepine-10,11-epoxide, which is thought to be responsible for the teratogenicity of the parent drug (Lindhout et al.,1984). This was confirmed in a study on pregnant mice where carbamazepine-10,11epoxide treatment significantly increased the incidence of malformations in foetuses (Bennett et al.,1996).

The result of this study referred to atrophy of renal glomeruli, degeneration of epithelial lining of renal tubules. These results are consistent with Okada, (2005), who confirmed that atrophy of glomeruli and degeneration of renal tubules leads to retarded renal growth. According to, Tatsunori (2010), concentrations of carbamazepine and its metabolites are much higher in the brain, lung, liver and kidney than its concentration in the blood. This suggests that the drug is retained in organ tissues and then this fact explains toxic effect of carbamazepine in kidney which represents as histopathological changes.

\section{Conclusion:-}

Histopathological changes of kidney due to developmental toxicity of carbamazepine represents as morphological changes and congenital anomaly of this organ depending on dosage of carbamazepine. Carbamazepine should be used cautiously during pregnancy, better restricted as much as possible during pregnancy. Further researches in human should be performed to verify these results.

\section{References:-}

1. Bauer J, Hermann A, Reuber M. 2002. Tolerance of high dosage carbamazepine monotherapy in treatment of epilepsy. Nervenarzt. V.73, N.6, 533-537.

2. Briggs GG, Freeman RK, Yaffe SJ. 1998. A Reference Guide to Fetal and Neonatal Risk. Drugs in Pregnancy and Lactation. 5th ed., Baltimore: Williams \& Wilkins., pp 220-223.

3. Davion T, Capron JP, Andrejak M, Geoffroy P, Capron-Chivrac D, Quénum C. 1984. Acute hepatitis due to carbamazepine (Tegretol). Study of a case and review of the literature. Gastroenterol. Clin Biol. , 8(1):52-6.

4. Okada A, Yabuki A, Matsumuto M, Suzuki S. 2005. Development of gender difference in DBA/2Cr mouse kidney morophology during maturation. J Vet Med Sci., 67:877-82.

5. Hayashi aci Toxnet HSDB, A. Yoshinaga, et al. (2005). "Asthenozoospermia: possible association with longterm exposure to an anti-epileptic drug of carbamazepine." Int J Urol 12(1): 113-114.

6. Perucca E. Birth defects after prenatal exposure to antiepileptic drugs. Lancet Neurolo 2005; 4:781-6. 
7. Barrett C, Richens A. Epilepsy and pregnancy: Report of an epilepsy research foundation workshop. Epilepsy Res 2003; 52:147- 87.

8. Morrow J, Russell A, Guthrie E, Parsons L, Robertson I, Waddell R, et al., Malformation risks of antiepileptic drugs in pregnancy: A prospective study from the UK Epilepsy and Pregnancy Register. J Neurol Neurosurg Psychiatry 2006; 77:193-8.

9. Holmes LB, Harvey EA, Coull BA, Huntington KB, Khoshbin S, Hayes AM et al., The teratogenicity of anticonvulsant drugs. N Engl J Med 2001; 344:1132-8.

10. Finnell RH, Chernoff GF. Mouse fetal hydantoin syndrome: Effects of maternal seizures. Epilepsia 1982; 23:423-9.

11. Samren EB, van Duijn CM, Christiaens GC, Hofman A, Lindhout D. Antiepileptic drug regimens and major congenital abnormalities in the offspring. Ann Neurol 1999; 46:739-46.

12. Afshar M, Hassanzadeh-Taheri MM, Moallem SA, Tamizi A, Golalipour MJ. Teratogenic effects of gabapentin on the skeletal system of Balb/C mice fetuses. Neurosciences (Riyadh) 2009; 14:239- 44.

13. Hunt S, Craig J, Russell A, Guthrie E, Parsons L, Robertson I, et al., Levetiracetam in pregnancy: Preliminary experience from the UK Epilepsy and Pregnancy Register. Neurology 2006; 67:1876-9.

14. Finnel, R.H., Mohl, V.K., Bennet, G.D., Taylor, S.M. (1986). Failure of epoxide formation to influence carbamazepine- induced teratogenesis in a mouse model. Teratol Carcinog Mutagen. Vol.6, No.5, (n.d.), pp.393-401, ISSN: 0270-3211.

15. Fritz, H., Müller, D., Hess, R. (1976). Comparative study of the teratogenicity of phenobarbitone, diphenylhydantoin and carbamazepine in mice. Toxicology. Vol.6, No.3, (November-December 1976), pp.323330, ISSN: 0300-483X.

16. Hanson, J.W., Smith, D.W. (1975). The fetal hydantoin syndrome. J Pediatr. Vol.87, No.2, (August 1975), pp.85-90. ISSN: 0022-3476.

17. Whitaker-Azmitia, P. M., Zhang, X., \& Clarke, C. (1994). Effects of gestational exposure to monoamine oxidase inhibitors in rats: preliminary behavioral and neurochemical studies. Neuropsychopharmacology, 11, 125-132. 